\title{
Total hip arthroplasty using a three- dimensional porous titanium acetabular cup: an examination of micromotion using subject-specific finite element analysis
}

Takaki Miyagawa, Kazu Matsumoto, Shingo Komura and Haruhiko Akiyama*

\begin{abstract}
Background: We investigated the mid-term clinical and radiological results of total hip arthroplasty (THA) using a three-dimensional (3D) porous titanium cup and analyzed the micromotion at the interface of the cup using subject-specific finite element (FE) analysis.

Methods: We evaluated 73 hips of 65 patients ( 6 men and 59 women; mean age at the time of surgery, 62.2 years; range, 45-86 years) who had undergone THA using a 3D porous titanium cup. Clinical evaluations were performed using the Japanese Orthopaedic Association (JOA) hip score system. We assessed the fixation of the acetabular component based on the presence of radiolucent lines and cup migration using anteroposterior radiographs. Subject-specific FE models were constructed from computed tomography data.

Results: The JOA score improved from a preoperative mean of 52.2 (range, 23-82) to a mean of 87.8 (range, 71100 ) at the final follow-up. None of the patients underwent revisions during the follow-up period. Radiolucent lines were observed in 26 cases (35.6\%) and frequently appeared at DeLee and Charnley Zone 3. Following the FE analysis, the micromotion at DeLee and Charnley Zone 3 was significantly larger than that at Zone 2. Furthermore, micromotion was large in the groups in which radiolucent lines appeared at Zone 3.

Conclusions: The mid-term clinical outcome of THA using a 3D porous titanium cup was excellent. However, radiolucent lines frequently appeared at DeLee and Charnley Zone 3. FE analysis indicated that micromotion was large at the same site, strongly suggesting that it contributes to the emergence of radiolucent lines. The 3D porous titanium cups are useful in THA, and with improvements focused on micromotion, we anticipate better long-term outcomes.
\end{abstract}

Keywords: Finite element analysis, Total hip arthroplasty, Three-dimensional porous structure, Radiolucent line

\section{Background}

According to national registration reports, the most common reason for revision surgery after total hip arthroplasty (THA) is aseptic loosening [1-3]. Similarly, the primary reason for revision surgery in Japan

\footnotetext{
* Correspondence: hakiyama@gifu-u.ac.jp

Department of Orthopaedic Surgery, Gifu University School of Medicine, Yanagido 1-1, Gifu 501-1194, Japan
}

is aseptic loosening of the acetabular component [4]. Loosening of the acetabular component is caused by osteolysis due to the abrasion powder of the polyethylene liner or poor fixation. To obtain long-term stable acetabular component fixation, biological fixation is required, and therefore, the initial fixation force and bone infiltration into the component porous region, are important $[5,6]$. 
Since 2000, acetabular components with a threedimensional (3D) structure in the porous region have been developed, and their use is associated with experimental efficacy and good survival rates [7-12]. The features of the $3 \mathrm{D}$ porous structure include a high friction coefficient and high porosity. Scratch fit caused by a high friction coefficient suppresses micromotion $[5,13$, 14] and higher porosity promotes bone infiltration into the interior of the porous region, resulting in long-term stability due to the interlocking of the acetabular component and bone [15].

However, in clinical reports of implants with a $3 \mathrm{D}$ porous structure, a high rate of radiolucent lines was observed [16-18]. Radiolucent lines are said to appear because of the fibrous fixation between the bone and components and occur with micromotion of $\geq 150 \mu \mathrm{m}$ [19].

The purposes of this study were to investigate the mid-term clinical results of THA using a $3 \mathrm{D}$ porous component, including the presence or absence of radiolucent lines, and to analyze the micromotion at the interface of the 3D acetabular component using finite element (FE) analysis.

\section{Methods}

Between May 2014 and May 2016, 66 patients (74 hips) underwent primary THA using the SQRUM TT (Fig. 1). One patient (one hip) was lost to follow-up. We, therefore, evaluated 73 hips of 65 patients $(6$ men and 59 women). Causative hip diseases for THA included dysplastic osteoarthritis of 63 hips, idiopathic osteonecrosis of 2 hips, rapidly destructive coxarthropathy of 2 hips, post-traumatic arthritis of 2 hips, rheumatoid arthritis of 1 hip, and post-infective arthritis of 1 hip. All patients underwent pre- and postoperative computed tomography $(\mathrm{CT})$. Preoperative $\mathrm{CT}$ was performed at the preoperative examination, and postoperative CT was performed 6 weeks after surgery. The implant used was the SQRUM TT (SQRUM TT ${ }^{\mathrm{T} M}$ socket; Kyocera, Kyoto, Japan). Cement or cementless stems were effectively used, depending on the shape and properties of the

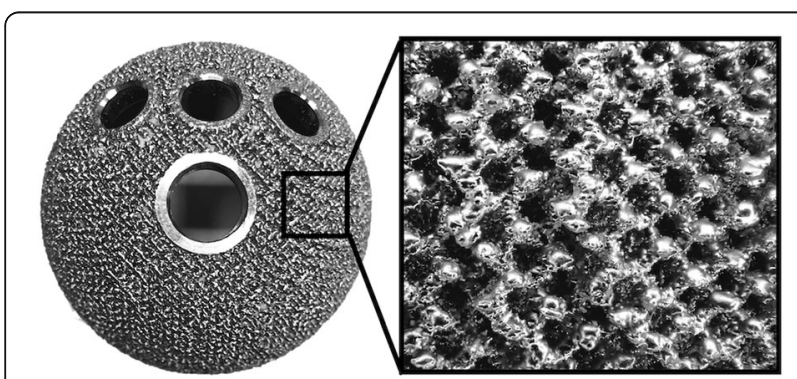

Fig. 1 A porous, hexagonal, tridimensional, multiplane structure obtained using an electron beam melting technique femur. SQRUM TT was only used when Kyocera's femoral stem and a cementless cup could be implanted. The specific design element of this prosthesis was a hexagonal tridimensional multiplane structure, which was made from titanium alloy (Ti6Al4V), obtained using an electron beam melting technique. The porosity was $60 \%$, the pore size was $640 \mu \mathrm{m}$, and the depth of porous structure was $1.2 \mathrm{~mm}$ (Fig. 1). Because of the design, the prosthesis had a solid cellular structure that was highly porous, mimicking natural cancellous bone and related elasticity (1.12 Gpa) [20, 21].

The operations were performed in a laminar-flow operating room, and patients received $1.0 \mathrm{~g}$ of cephalosporin intravenously immediately before surgery for antibiotic prophylaxis. Surgical procedures were performed using a direct lateral approach with the patient in the lateral position [22-24]. Acetabular reaming was performed using the same diameter as the outer diameter of the installation cup, and three screws were used to reinforce the initial fixing force.

\section{Clinical evaluation}

Clinical evaluations were performed preoperatively and at the final follow-up using the Japanese Orthopaedic Association hip score system, in which the maximum score of 100 points was divided into a 'pain' score (40 points), 'range of motion' score (20 points), 'walking ability' score (20 points), and 'activity of daily living' score (20 points). A higher score indicated a better condition $[25,26]$. Intraoperative and postoperative complications were also investigated.

\section{Radiological evaluation}

We assessed the fixation of the acetabular component based on the presence of radiolucent lines and cup migration using anteroposterior radiographs. The presence of radiolucent lines in the three acetabular zones of DeLee and Charnley [27] was evaluated using three types divided into five stages as advocated by Long et al. [28] Cup migration was investigated by changing the position of the acetabular component and the inclination angle [29]. The superior position of the cup center was also measured in relation to the distance between the bottom of the teardrop and the center of the cup. The lateral position of the cup center was also measured as the horizontal distance between the bottom of the teardrop and the perpendicular point on the inter-teardrop line from the center of the cup. Cup inclination was determined using a horizontal reference line drawn through the base of the teardrops [30].

\section{FE analysis}

CT scans (Brilliance64; Philips, Best, Netherlands) of the pelvis were acquired pre- and postoperatively. The 


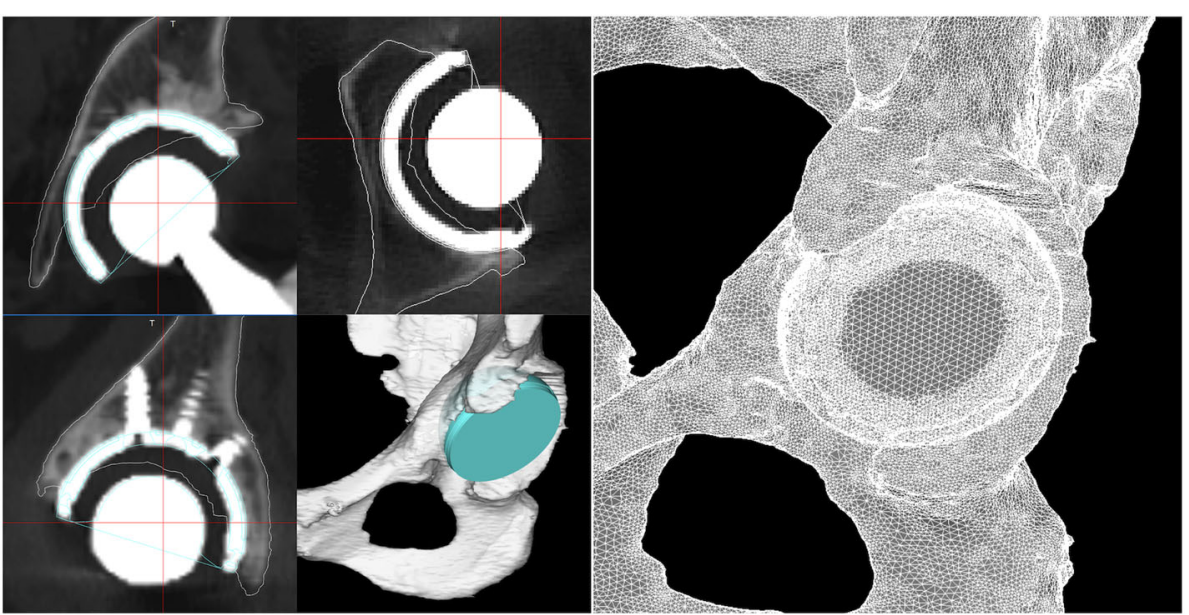

Fig. 2 Finite element model of a pelvis and acetabular component created to match the postoperative location. By creating a pelvic region of interest from preoperative computed tomography $(\mathrm{CT})$ and synthesizing it with implant Computer Aided Design data on postoperative $\mathrm{CT}$, the postoperative condition is reproduced without the effect of halation caused by the implant

scanner settings were approximately $120 \mathrm{kV}, 0.68 \times$ $0.68 \times 1-\mathrm{mm}$ voxel size. FE models of the pelvis were generated from pre- and postoperative CT data using Mechanical Finder (MF) version 11.0 (Research Centre of Computational Mechanics, Inc., Tokyo, Japan). Only region of interest (ROI) models were semi-automatically constructed in 3D-planning software; Zed View version 12.0 (LEXI, Tokyo, Japan). The acetabular component Computer Aided Design data were precisely placed in the pelvic ROI model by matching the postoperative CT perfectly in Zed View. A composite ROI of the pelvis and acetabular components was imported into the MF for analysis (Fig. 2).

This created an FE model that indicated the shape of the individual bone and the distribution of its density [31]. Within this software, FE mesh models were generated using Ansys ICEM CFD version 19.0 (Ansys Inc., Canonsburg, Pennsylvania), and modelled as a 0.5-2.0 $\mathrm{mm}$ tetrahedral element for cancellous and medial cortical bone.

The analysis was performed with the elastic modulus of the porous region of the SQRUM TT being $1.12 \mathrm{Gpa}$

Table 1 Equations used to calculate the elastic modulus of the bone

\begin{tabular}{ll}
\hline Bone density & Elastic modulus (MPa) \\
\hline$P=0$ & 0.001 \\
$0<p \leq 0.27$ & $33900 p^{2.20}$ \\
$0.27<p<0.6$ & $5307 p+469$ \\
$0.6 \leq p$ & $10200 p^{2.01}$ \\
\hline
\end{tabular}

The elastic modulus of the bone is based on computed tomography density values, using the equations proposed by Keyak et al. [32]

$\mathrm{p}\left(\mathrm{g} / \mathrm{cm}^{3}\right)=(\mathrm{H} . \mathrm{U} .+1.4246) \times 0.001 / 1.058(\mathrm{H} . \mathrm{U} .>-1)=0.0(\mathrm{H} . \mathrm{U} . \leq-1)$ H. U. Hounsfield units. and Poisson's ratio being 0.44. When the SQRUM TT was implanted, the tremor under load was calculated for each region. The pelvic FE model consisted of approximately 2.5 million elements. The elastic modulus of the bone was determined from the CT density values using the equation proposed by Keyak et al. [32] (Table 1). The bone Poisson's ratio was 0.40 . The model was analyzed assuming an interface where the pelvic and acetabular components are in contact with a coefficient of friction of 1.02. Regarding the applied load condition, assuming one-leg standing, the upper region of the pelvis was completely fixed, and $1980 \mathrm{~N}$, which is 3.3-fold the body weight based on Pauwels' theory [33], was added to the functional axis from the knee joint center to the femoral head center.

Eight FE models were prepared using 50-mm cups and 28-mm heads, four of which had radiolucent lines clinically. The elemental nodes of the porous part included in

Table 2 Patient demographics

\begin{tabular}{ll}
\hline Sex $(\mathrm{n})$ & \\
Male & 6 (7 hips) \\
Female & 59 (66 hips) \\
Age, mean (range) (years) & $62.2(45-86)$ \\
Height, mean (range) (cm) & $152.9(133.8-171.6)$ \\
Weight, mean (range) $(\mathrm{kg})$ & $54.4(34.0-73.8)$ \\
Body mass index, mean (range) $\left(\mathrm{kg} / \mathrm{m}^{2}\right)$ & $23.3(15.1-30.8)$ \\
Crowe classification (n) & \\
Group I & 59 \\
Group II & 10 \\
Group III & 3 \\
Group IV & 1 \\
\hline
\end{tabular}




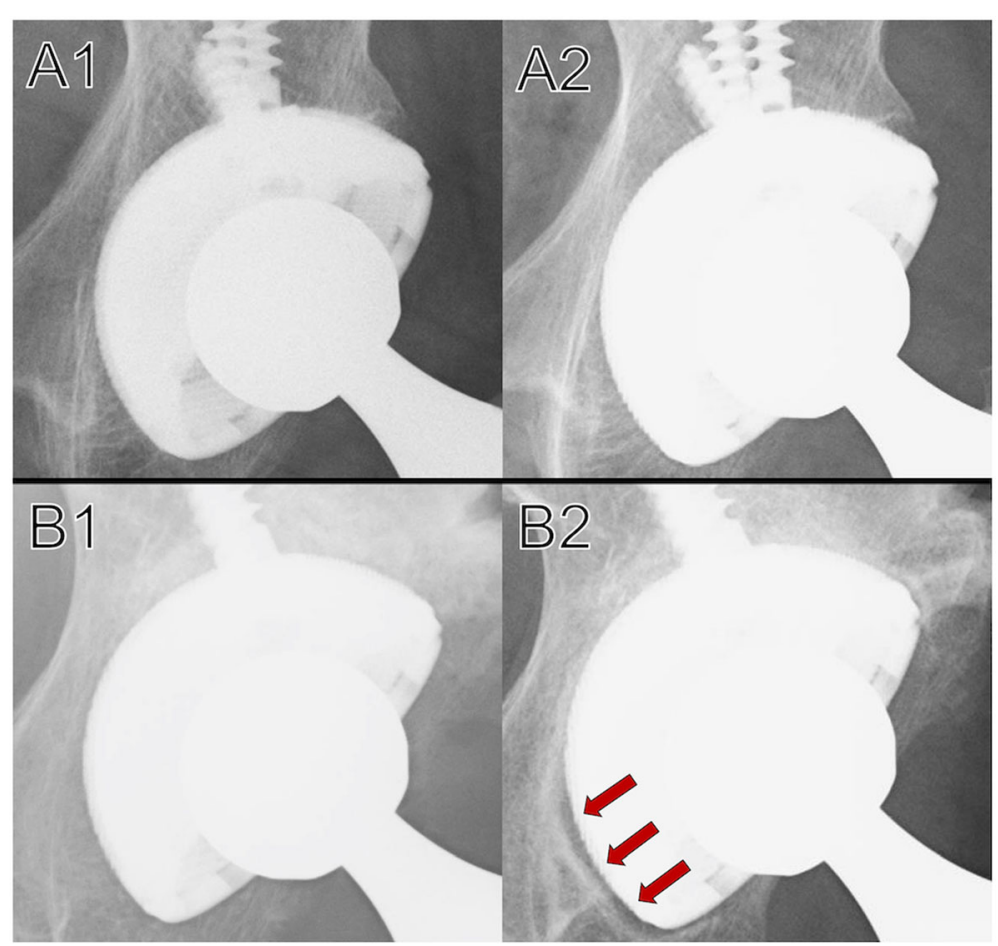

Fig. 3 Radiograph images in which radiolucent lines did not appear and where they did appear. A1, B1: There is no initial gap on the anteroposterior radiograph immediately after surgery. A2: There is no radiolucent line around the cup 2 years after surgery. B2: Two years after the operation, radiolucent lines are observed in DeLee and Charnley Zone 3 (red arrows)

the radius of $3 \mathrm{~mm}$ were extracted at the three points corresponding to the zones of DeLee and Charnley, and the relative movement distance with the elemental nodes of the adjacent bones corresponding to these was defined as micromotion.

\section{Statistical analysis}

Statistical analyses were conducted using GraphPad Prism Version 5.01 (GraphPad Software, La Jolla, CA). Intraclass correlation coefficients (ICCs) were used to assess the intra- and inter-observer (two observers) reliabilities of the cup inclination and the cup migration measurements. ICC values can range from 0 to 1 , with a higher value indicating better reliability. ICC values were analyzed in accordance with a previously described semi-quantitative scale $(0-0.20$, slight agreement; $0.21-0.40$, fair; $0.41-0.60$, moderate; $0.61-$ 0.80 , substantial; and $0.81-1.0$, almost perfect) [34]. A paired t-test was used to analyze changes in radiological measurements. The micromotion of the three groups was compared using one-way analysis of variance and the Dunn-Bonferroni test. An unpaired ttest was performed to compare the micromotions of the groups with and without the radiolucent line. A $p$-value of $<0.05$ indicated statistical significance. Additionally, statistical power analysis was performed using G*Power 3.1.9.4 with an $\alpha$ level of $5 \%$.

\section{Results}

Demographic characteristics

Patient demographics are shown in Table 2. Briefly, the mean age of the patients at the time of surgery

Table 3 Modified DeLee and Charnley skeletal fixation score for the acetabulum

\begin{tabular}{llll}
\hline & Fixation grade & Radiolucency by zone & Hips (n) \\
\hline Bone ingrowth, stable & IA & None & 47 \\
& IB & One zone & Two zone \\
Fibrous ingrowth, stable & IC & Complete RLL < 2 mm all zones & 4 \\
Fibrous fixation, unstable & II & Progressive RLL Zone 3, complete RLL & 1 \\
& III & $\geq 2 \mathrm{~mm}$ all zones, or socket migration & 0 \\
\hline
\end{tabular}


was 62.2 years (range, 45-86 years), and the mean clinical follow-up was 5.3 years (range, $4.3-6.3$ years).

\section{Clinical results}

Paired t-tests showed that the Japanese Orthopaedic Association hip score significantly improved from a preoperative mean of 52.2 (range, 23-82) to a mean of 87.8 (range, 71-100) at the final follow-up ( $p<$ 0.01 ). One patient developed sciatic nerve disorder, but the symptoms improved during follow-up. Mild ectopic ossification and dislocation were each observed in one patient. No patients underwent revisions during the follow-up period.

\section{Radiological results}

The mean (standard deviation [SD], range) cup inclination angles were $44.4^{\circ}(4.75,33.1-57.3)$ immediately after the operation and $44.8^{\circ}(4.95,33.1-59.4)$ at the final observation. There was a significant difference between the angle immediately after surgery and at the final observation $(p<0.05)$. There was a case in which the angle increased by $\geq 3^{\circ}$, but no migration was observed. There was no significant change in the movement distance of the center of the cup in the vertical (mean, $0.16 \mathrm{~mm}, p=0.123$ ) and horizontal (mean, $0.17 \mathrm{~mm}, p=0.27$ ) directions from immediately after surgery until the final observation.

Initial gaps were observed in 14 hips, but gap filling occurred in all cases during follow-up. Radiolucent lines were observed in only one DeLee and Charnley zone in 21 hips, in two zones in four hips, and in three zones in one hip (Fig. 3). No enlargement of the radiolucent line was observed by the final observation. When comparing the zones, the radiolucent lines appeared most frequently in Zone 3 (Tables 3, 4).

Two intra-observer ICCs were calculated; both were $\geq 0.9$ for the radiographic measurements. The inter-observer ICCs were $\geq 0.8$. These values indicate an agreement between different radiographic measurements.

\section{FE analysis}

In the study of micromotion, the relative movement distances of the element nodes were calculated to compare the three points corresponding to the zone of DeLee and Charnley (Fig. 4). The analysis was performed

Table 4 Total number and area of radiolucent lines

\begin{tabular}{ll}
\hline DeLee and Charnley Zone & $\mathbf{n}$ \\
\hline Zone 1 & 6 \\
Zone 2 & 4 \\
Zone 3 & 22 \\
\hline
\end{tabular}

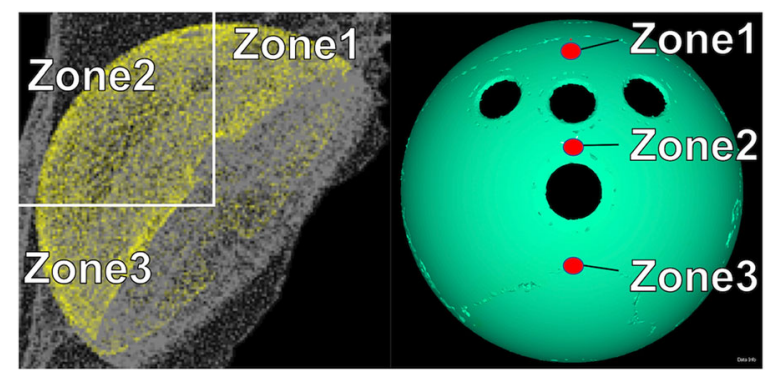

Fig. 4 Finite element model of the porous part used in micromotion analysis. Element nodes were extracted from the locations corresponding to DeLee and Charnley Zones 1 to 3 of the porous region, and micromotion analysis was performed

with eight models, four cases in which the radiolucent line appeared and four cases in which the radiolucent line did not appear, and 15 to 40 element nodes were extracted for each point (Fig. 5).

By defining the mean of each point in each model as the micromotion, the micromotions of Zone 3 and Zone 1 were significantly greater than that of Zone 2 . There was no significant difference between Zone 3 and Zone 1, but micromotion at Zone 3 tended to be large (Fig. 6).

Furthermore, a comparison of cases with and without radiolucent lines revealed that micromotion was large in the cases in which radiolucent lines appeared at Zone 3 (Fig. 7).

\section{Discussion}

The 3D highly porous metal cups are characterized by various features such as osteoinductive ability due to high porosity, reduction of stress shielding by elastic modulus close to cancellous bone, and high fracture strength of the porous region [21, 35-37]. It has been reported that the SQRUM TT, which was used in this study, can obtain biological immobilization from an early stage via the suppression of micromotion by scratch fit and physiological load transmission by the elastic modulus of the porous region similar to cancellous bone [10]. In our study, there were no cases of mid-term aseptic loosening, and no cases required reoperation for any reason.

Following the radiological examination, the initial gap disappeared during follow-up, but radiolucent lines were observed in 26 of 73 cases (35.6\%). All cases were stable with a grade of II or higher according to the Modified DeLee and Charnley skeletal fixation score for the acetabulum. Imai et al. [16] also reported the presence of radiolucent lines, and it has been said that radiolucent lines appear in groups with less osteophyte formation.

In this study, the reason underlying the frequent appearance of radiolucent lines in DeLee and Charnley Zone 3 was analyzed using an FE model, 


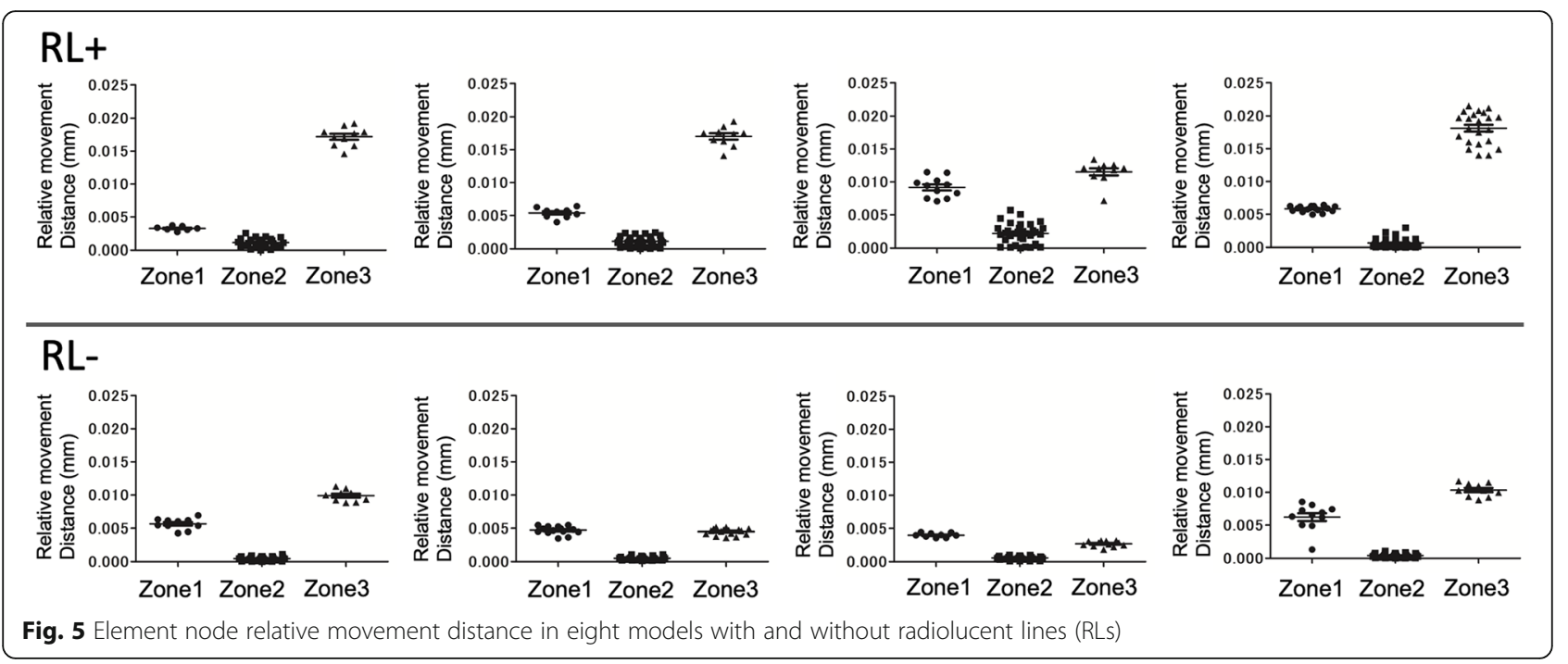

focusing on micromotion during single leg standing. The micromotion at the point corresponding to DeLee and Charnley Zone 3 was significantly larger than that corresponding to Zone 2. Furthermore, the comparison of cases in which radiolucent lines did and did not appear indicated that micromotion was large in cases in which radiolucent lines appeared at the points corresponding to DeLee and Charnley Zone 3. These results suggest that the frequent appearance of radiolucent lines in DeLee and Charnley Zone 3 could be due to micromotion. Furthermore, SQRUM TT has a low modulus of elasticity in the porous region and close to the cancellous bone, which is designed to cause physiological load transmission and avoid stress shielding [21]. The result of the FE analysis focusing on the elastic modulus of the porous region suggested that the low elastic modulus may contribute to the generation of micromotion.

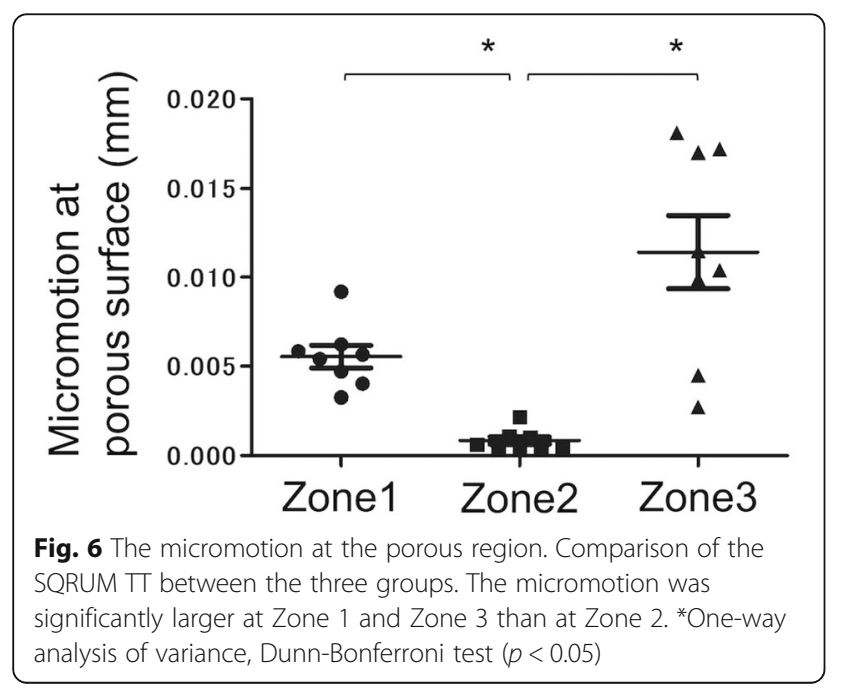

Porous factors, which determine the performance of a cementless acetabular component, are important and include porous design, surface processing, and metal species. A successful 3D porous structure requires not only the porosity and friction coefficient, but also the elastic modulus, which predicts micromotion. To date, surface treatments such as hydroxyapatite-coated and alkaline heat treatment have been applied to the porous area, and several authors have reported good clinical results [38-41]. As a material, a highly porous tantalum cup has been described to have good clinical results [7-9]. To achieve long-term results, further improvements in cementless cups are required, such as a combination of these elements.

When performing pressure load tests using cadaver bones, it is difficult to accurately evaluate the stress on the contact surface from the acetabular component implanted and the micromotion at the time of loading. Therefore, the FE analysis method presented here will aid the study of micromotion of the acetabular component, particularly focusing on the elastic modulus of the porous region.

The limitations of this study include the lack of implant survival rate evaluation over a long period as part of the clinical evaluation, limited number of FE analysis cases, and lack of implant size analysis. There was a significant difference in the cup inclination angle from immediately after surgery to the final observation, but the difference was minimal, and it is possible that postoperative changes in pelvic tilt had an effect. In addition, the analysis was performed only under the one-leg standing condition. In future studies, analysis under conditions such as walking and moving up and down stairs will provide more detailed results that reproduce more realistic phenomena. 


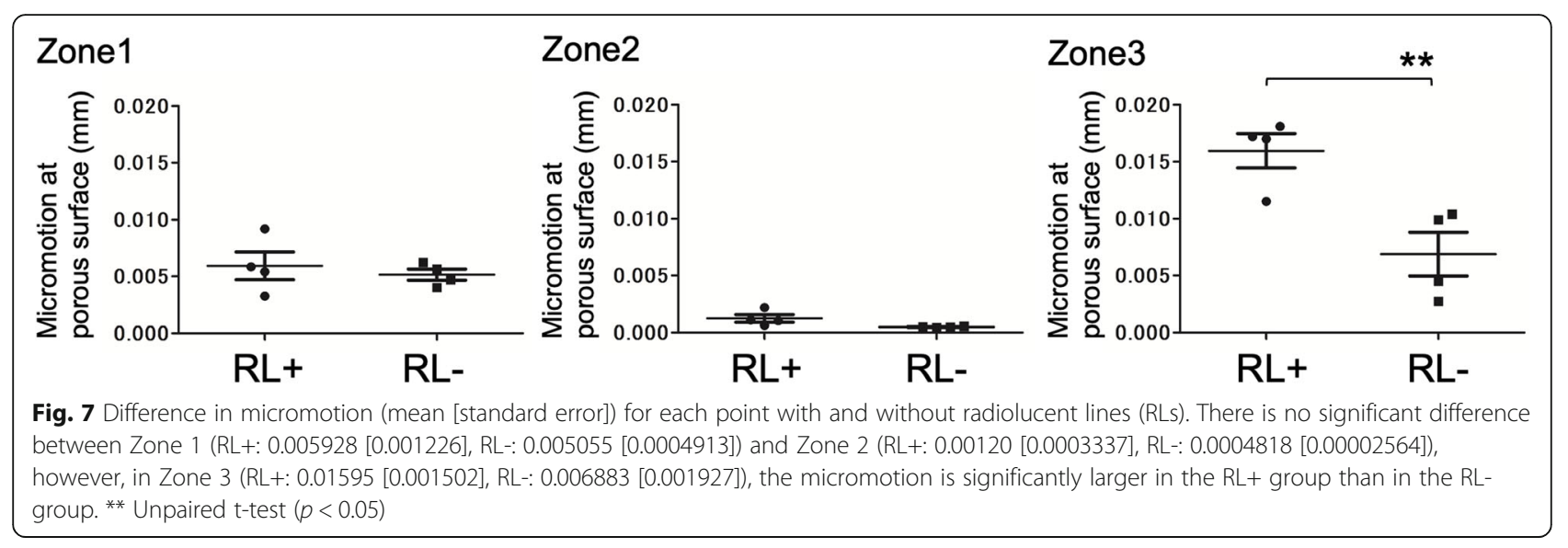

\section{Conclusion}

The mid-term clinical outcome of THA using a 3D porous titanium cup was excellent. An examination of micromotion by FE analysis showed that the emergence of radiolucent lines was predictable. Future improvements in implants with this research method can lead to longer-term clinical results.

\section{Abbreviations}

THA: Total hip arthroplasty; 3D: Three-dimensional; FE: Finite element; JOA: Japanese Orthopaedic Association; CT: Computed tomography; ROI: Region of interest; ICCs: Intraclass correlation coefficients

\section{Acknowledgements}

Not applicable.

\section{Authors' contributions}

T.M. proposed the research project, designed the experiments, corrected data and wrote the manuscript. T.M. and H.A. performed the operations. S.K., K.M., and H.A. provided instructions for data analysis and drafting the manuscript. All authors read and approved the final manuscript.

\section{Funding}

Not applicable.

\section{Availability of data and materials}

The datasets used and/or analyzed during the current study are available from the corresponding author on reasonable request.

\section{Declarations}

Ethics approval and consent to participate

All procedures performed were in accordance with the 1964 Helsinki Declaration. Ethical approval was obtained (29-371) from the Ethics Commission of the Gifu University Graduate School of Medicine. Informed consent was obtained using an opt-out method posted in an outpatient setting.

\section{Consent for publication}

Not applicable.

\section{Competing interests}

The authors declare that they have no competing interests.
Received: 26 January 2021 Accepted: 15 March 2021

Published online: 26 March 2021

\section{References}

1. Australian Orthopaedic Association National Joint Replacement Registry: Hip, knee \& shoulder arthroplasty: 2017 annual report. 2017. https://aoan-jrr. sahmri.com/documents/10180/397736/Hip\%2C\%20Knee\%20\%26\%20Shoulder\%20Arthroplasty. Accessed 29 Nov 2020.

2. Kärrholm J LH, Malchau H, et al. The Swedish Hip Arthroplasty Register: annual report 2016. 2016. https://registercentrum.blob.core.windows.net/ shpr/r/Annual-Report-2016-B1eWEH-mHM.pdf Accessed 29 Nov2020.

3. National Joint Registry for England, Wales NI and I of M. 15th Annual Report. 2018. http://www.njrcentre.org.uk. Accessed 29 Nov 2020.

4. Japanese THA registory, 2018. https://jsra.info/pdf/THA20180331.pdf. Accessed 11 November 2020.

5. Curtis MJ, Jinnah RH, Wilson VD, Hungerford DS. The initial stability of uncemented acetabular components. J Bone Joint Surg (Br). 1992;74:372-6.

6. Saleh KJ, Bear B, Bostrom M, Wright T, Sculco TP. Initial stability of press-fit acetabular components: an in vitro biomechanical study. Am J of orthop (Belle Mead, NJ). 2008;37:519-22.

7. Nakashima Y, Mashima N, Imai H, Mitsugi N, Taki N, Mochida Y, Owan I, Arakaki K, Yamamoto T, Mawatari T, Motomura G, Ohishi M, Doi T, Kanazawa M, Iwamoto Y. Clinical and radiographic evaluation of total hip arthroplasties using porous tantalum modular acetabular components: 5year follow-up of clinical trial. Mod Rheumatol. 2013;23(1):112-8. https://doi. org/10.3109/s10165-012-0618-9.

8. Meneghini RM, Ford KS, McCollough CH, Hanssen AD, Lewallen DG. Bone remodeling around porous metal cementless acetabular components. J Arthroplast. 2010;25(5):741-7. https://doi.org/10.1016/j.arth.2009.04.025.

9. Macheras GA, Lepetsos P, Leonidou AO, Anastasopoulos PP, Galanakos SP, Poultsides LA. Survivorship of a porous tantalum monoblock acetabular component in primary hip arthroplasty with a mean follow-up of 18 years. J Arthroplast. 2017;32(12):3680-4. https://doi.org/10.1016/j.arth.2017.06.049.

10. Perticarini L, Zanon G, Rossi SM, Benazzo FM. Clinical and radiographic outcomes of a trabecular titanium acetabular component in hip arthroplasty: results at minimum 5 years follow-up. BMC Musculoskelet Disord. 2015;16(1):375. https://doi.org/10.1186/s12891-015-0822-9.

11. De Meo F, Cacciola G, Bellotti V, Bruschetta A, Cavaliere P. Trabecular titanium acetabular cups in hip revision surgery: mid-term clinical and radiological outcomes. Hip Int. 2018;28(Suppl 2):61-5. https://doi.org/10.11 77/1120700018812992.

12. Banerjee S, Issa K, Kapadia BH, Pivec R, Khanuja HS, Mont MA. Highly-porous metal option for primary cementless acetabular fixation. What is the evidence? Hip Int. 2013;23(6):509-21. https://doi.org/10.5301/hipint.5000064.

13. Issack PS. Use of porous tantalum for acetabular reconstruction in revision hip arthroplasty. J Bone Surg Am. 2013;95(21):1981-7. https://doi.org/10.21 06/JBJS.L.01313.

14. Otsuki B, Takemoto M, Fujibayashi S, Neo M, Kokubo T, Nakamura T. Pore throat size and connectivity determine bone and tissue ingrowth into porous implants: three-dimensional micro-CT based structural analyses of 
porous bioactive titanium implants. Biomaterials. 2006;27(35):5892-900. https://doi.org/10.1016/j.biomaterials.2006.08.013.

15. Urban RM, Hall DJ, Della Valle C, Wimmer MA, Jacobs JJ, Galante JO Successful long-term fixation and progression of osteolysis associated with first-generation cementless acetabular components retrieved post mortem. J Bone Joint Surg Am. 2012:94(20):1877-85. https://doi.org/1 $0.2106 / J B J S . J .01507$

16. Imai H, Miyawaki J, Kamada T, Maruishi A, Takeba J, Miura H. Radiolucency around highly porous sockets and hydroxyapatite-coated porous sockets in total hip arthroplasty for hip dysplasia. Eur J Orthop Surg Traumatol. 2019; 29(3):611-8. https://doi.org/10.1007/s00590-018-2351-3.

17. Yoshioka S, Nakano S, Kinoshita Y, Nakamura M, Goto T, Hamada D, Sairyo K. Comparison of a highly porous titanium cup (Tritanium) and a conventional hydroxyapatite-coated porous titanium cup: a retrospective analysis of clinical and radiological outcomes in hip arthroplasty among Japanese patients. J Orthop Sci. 2018;23(6):967-72. https://doi.org/10.1016/j.jos.2018. 06.018.

18. Carli AV, Warth LC, de Mesy Bentley KL, Nestor BJ. Short to midterm followup of the tritanium primary acetabular component: a cause for concern. J Arthroplast. 2017;32(2):463-9. https://doi.org/10.1016/j.arth.2016.07.024.

19. Pilliar RM, Lee JM, Maniatopoulos C. Observations on the effect of movement on bone ingrowth into porous-surfaced implants. Clin Orthop Relat Res. 1986;1:108-13.

20. Ding M. Age variations in the properties of human tibial trabecular bone and cartilage. Acta Orthop Scand Suppl. 2000;292:1-45.

21. Marin E, Fusi S, Pressacco M, Paussa L, Fedrizzi L. Characterization of cellular solids in Ti6Al4V for orthopaedic implant applications: trabecular titanium. J Mech Behav Biomed Mater. 2010;3(5):373-81. https://doi.org/10.1016/j. jmbbm.2010.02.001.

22. Berger RA. Mini-incision total hip replacement using an anterolateral approach: technique and results. Orthop Clin North Am. 2004;35(2):143-51. https://doi.org/10.1016/S0030-5898(03)00111-1.

23. Hardinge K. The direct lateral approach to the hip. J Bone Joint Surg (Br). 1982;64:17-9.

24. Kuroda Y, Akiyama H, Nankaku M, So K, Matsuda S. Modified Mostardi approach with ultra-high-molecular-weight polyethylene tape for total hip arthroplasty provides a good rate of union of osteotomized fragments. J Orthop Sci. 2015;20(4):633-41. https://doi.org/10.1007/s00776-015-0721-9.

25. Ogawa H, Ito Y, Itokazu M, Mori N, Terabayashi N, Shimizu K. Cementless total hip arthroplasty using a spongy metal surface hip prosthesis with a collarless, proximally porous-coated stem. J Arthroplast. 2010;25(3):375-80. https://doi.org/10.1016/..arth.2009.01.012.

26. Hasegawa Y, Iwata H, Mizuno M, Genda E, Sato S, Miura T. The natural course of osteoarthritis of the hip due to subluxation or acetabular dysplasia. Arch Orthop Trauma Surg. 1992;111(4):187-91. https://doi.org/10.1 007/BF00571474.

27. DeLee JG, Charnley J. Radiological demarcation of cemented sockets in total hip replacement. Clin Orthop Relat Res. 1976;1:20-32.

28. Long WT, Dorr LD, Healy B, Perry J. Functional recovery of noncemented total hip arthroplasty. Clin Orthop Relat Res. 1993;288:73-7.

29. Callaghan JJ, Dysart SH, Savory CG. The uncemented porous-coated anatomic total hip prosthesis. Two-year results of a prospective consecutive series. J Bone Joint Surg Am. 1988;70(3):337-46. https://doi.org/10.2106/ 00004623-198870030-00004.

30. Kaneuji A, Sugimori T, Ichiseki T, Yamada K, Fukui K, Matsumoto T. Minimum ten-year results of a porous acetabular component for Crowe I to III hip dysplasia using an elevated hip center. J Arthroplast. 2009;24(2):187-94. https://doi.org/10.1016/j.arth.2007.08.004.

31. Bessho M, Ohnishi I, Matsuyama J, Matsumoto T, Imai K, Nakamura K. Prediction of strength and strain of the proximal femur by a CT-based finite element method. J Biomech. 2007;40(8):1745-53. https://doi.org/10.1016/j. jbiomech.2006.08.003.

32. Keyak JH, Rossi SA, Jones KA, Skinner HB. Prediction of femoral fracture load using automated finite element modeling. J Biomech. 1998;31(2):125-33. https://doi.org/10.1016/s0021-9290(97)00123-1.

33. Pauwels. Diseases of the hip of mechanical origin and their treatment by adduction osteotomy. Rev Chir Orthop Reparatrice Appar Mot. 1951;37: 22-30.

34. Landis JR, Koch GG. The measurement of observer agreement for categorical data. Biometrics. 1977:33(1):159-74. https://doi.org/10.2307/2 529310.
35. Medlin D, Scrafton J, Shetty R. Metallurgical attachment of a porous tantalum foam to a titanium substrate for orthopedic applications. J ASTM Int. 2005;2:1-10.

36. Bobyn JD, Stackpool GJ, Hacking SA, Tanzer M, Krygier JJ. Characteristics of bone ingrowth and interface mechanics of a new porous tantalum biomaterial. J Bone Joint Surg (Br). 1999:81(5):907-14. https://doi.org/10.13 02/0301-620X.81B5.0810907.

37. Small SR, Berend ME, Howard LA, Rogge RD, Buckley CA, Ritter MA. High initial stability in porous titanium acetabular cups: a biomechanical study. J Arthroplast. 2013;28(3):510-6. https://doi.org/10.1016/j.arth.2012.07.035.

38. Kawanabe K, Ise K, Goto K, Akiyama H, Nakamura T, Kaneuji A, et al. A new cementless total hip arthroplasty with bioactive titanium porous-coating by alkaline and heat treatment: average 4.8-year results. J Biomed Mater Res B Appl Biomater. 2009;90:476-81.

39. Mann CJ, McNally S, Taylor E, Shepperd JA. A retrospective clinical and radiographic review of 173 hydroxyapatite-coated screw cups with 5- to 10year follow-up, showing low revision rates for fixation failure. J Arthroplast. 2002;17(7):851-5. https://doi.org/10.1054/arth.2002.34825.

40. Baker PN, MCMurtry IA, Chuter G, Port A, Anderson J. THA with the ABG I prosthesis at 15 years. Excellent survival with minimal osteolysis. Clin Orthop Relat Res. 2010;468(7):1855-61. https://doi.org/10.1007/s11999-009-1066-5.

41. Rogers A, Kulkarni R, Downes EM. The ABG hydroxyapatite-coated hip prosthesis: one hundred consecutive operations with average 6-year followup. J Arthroplast. 2003;18(5):619-25. https://doi.org/10.1016/S0883-5403(03 )00208-0.

\section{Publisher's Note}

Springer Nature remains neutral with regard to jurisdictional claims in published maps and institutional affiliations.
Ready to submit your research? Choose BMC and benefit from:

- fast, convenient online submission

- thorough peer review by experienced researchers in your field

- rapid publication on acceptance

- support for research data, including large and complex data types

- gold Open Access which fosters wider collaboration and increased citations

- maximum visibility for your research: over $100 \mathrm{M}$ website views per year

At BMC, research is always in progress.

Learn more biomedcentral.com/submissions 